\title{
Français et immigrés en temps de crise (1930-1980),
} Schor Ralph

Paris, L'Harmattan collection « Populations », 2004, 242 p. ISBN :

2-7475-6798-2

Yves Charbit

\section{OpenEdition}

\section{Journals}

Édition électronique

URL : https://journals.openedition.org/remi/4276

DOI : $10.4000 /$ remi.4276

ISSN : $1777-5418$

Éditeur

Université de Poitiers

\section{Édition imprimée}

Date de publication : 1 juin 2005

Pagination : 166-167

ISBN : 2-911627-40-7

ISSN : 0765-0752

Référence électronique

Yves Charbit, "Français et immigrés en temps de crise (1930-1980), Schor Ralph », Revue européenne des migrations internationales [En ligne], vol. 21 - n² | 2005, mis en ligne le 01 octobre 2008, consulté le 15 avril 2022. URL : http://journals.openedition.org/remi/4276 ; DOI : https://doi.org/10.4000/remi. 4276

Ce document a été généré automatiquement le 15 avril 2022.

(c) Université de Poitiers 


\section{Français et immigrés en temps de crise (1930-1980), Schor Ralph}

Paris, L'Harmattan collection « Populations », 2004, 242 p. ISBN :

2-7475-6798-2

Yves Charbit

\section{RÉFÉRENCE}

Français et immigrés en temps de crise (1930-1980), Schor Ralph, Paris, L'Harmattan collection « Populations », 2004, 242 p. ISBN : 2-7475-6798-2

1 D'emblée, le titre du dernier ouvrage de Ralph Schor indique la perspective comparatiste adoptée par l'auteur: à cinquante ans d'écart, la France se trouve confrontée à la crise économique et au chômage et dans les deux cas, une des composantes de la société française est la présence des immigrés. La comparaison peutelle être établie ? C'est le pari que prend l'auteur.

2 Le plan suivi, qui est thématique, part de l'analyse de la concurrence et de la manière dont la peur du chômage qui lui est associée est exploitée par l'argumentaire nationaliste. Celui-ci n'a guère changé entre 1930 et 1980, les solutions réclamées ou appliquées sont les mêmes - arrêt de l'immigration et renforcement des mesures d'expulsion - et les pouvoirs publics accusés de ne pas adopter des mesures suffisamment énergiques. Ralph Schor note que l'extrême droite n'est nullement isolée : l'opinion publique, de manière certes plus modérée, rejoint ses thèses. C'est qu'au cœur des attitudes à l'égard de l'immigration règne une xénophobie que l'auteur analyse ensuite, en montrant qu'elle se généralise depuis le secteur de l'emploi jusqu'au social, au culturel et au politique : la concurrence pour les logements, le risque des maladies contagieuses attribué à l'origine géographique des étrangers, la délinquance, le nivellement par le bas de l'éducation, donnent lieu à des discours et des déclarations politiques et des articles de presse dont seuls le style et le vocabulaire changent, mais qui renvoie à la même logique : les étrangers sont responsables de la situation. 
3 Au niveau politique, longuement et finement analysé par Ralph Schor, la rhétorique de la France, terre d'asile est constamment mise à mal devant le constat de l'afflux des réfugiés dans les années 1930, d'autant que les organisations politiques et syndicales craignent de se couper de l'opinion publique. L'histoire se répète avec les Sarrois, les Juifs étrangers, les réfugiés espagnols, tandis que les attentats commis par les étrangers en 1937 s'inscrivent dans un contexte de tensions internationales où le nationalisme français se sent menacé par l'anarchie et les agitateurs communistes téléguidés par Moscou. En 1980, le débat autour du droit d'asile relève d'une autre logique: la revendication de ce droit ne masque-t-il pas une tentative d'immigration économique? Autre caractéristique des années 1980, la récurrente question des droits politiques des étrangers que la gauche, quand elle est au pouvoir, utilise pour diviser la droite, sans jamais vraiment mettre en pratique cette mesure annoncée dès 1972 par le Programme commun de la gauche. Ces questions débouchent sur un problème central, celui de l'identité nationale, qui est perçue comme «mise en péril » en 1930 dans un contexte de dénatalité et en 1970 et 1980 avec le concept de seuil de tolérance qui cristallise l'idée d'invasion, puis avec l'affaire du foulard islamique, qui symbolise un Islam conquérant.

4 Aussi n'est-il guère surprenant que la xénophobie ait très vite abouti au développement du racisme et de l'antisémitisme. Dans les années 1930, avec l'empire colonial, il prend la forme de la supériorité de la race blanche, et avec le nationalisme ambiant, fleurissent les stéréotypes nationaux. Dans les années 1980, "l'autocensure semble peser sur les penchants racistes». Le mot important, ici, est «semble», car R. Schor montre la dégradation de la situation: passage progressif des paroles insidieuses aux insultes puis aux agressions physiques, tandis que le racisme se dote d'une respectabilité pseudo culturelle avec Charles Maurras, puis pseudo scientifique avec le GRECE.

5 Rapprocher les deux crises, celle des années trente et celle qui a suivi la crise pétrolière de 1974 et particulièrement éclairant et l'auteur, spécialiste des questions migratoires apporte le regard de l'historien dans un champ de recherche où, faute de profondeur, les opinions et jugements exprimés sur la crise ignorent souvent les situations précédentes. À y regarder de plus près, les similitudes l'emportent sur les différences, ce qui conduit à s'interroger sur la permanence des constats. Si l'immigration s'analyse, pour ce qui est de ses conséquences économiques, sociales, politiques, de la même manière à cinquante ans d'écart, c'est que l'immigration dans la société française est bel et bien une caractéristique structurelle. Seuls changent les acteurs en présence, la nature des enjeux. Prenons un exemple précis : la disparition de secteurs entiers de l'économie française a sûrement fait vieillir les analyses relatives au "remplacement " des ouvriers au bas de l'échelle sociale par des immigrés. En 1980, la thématique de la " concurrence " exploitée par l'extrême droite, continue à susciter des réactions de rejet, tout comme dans les années trente. Et pourtant, la classe ouvrière n'occupe plus la même place dans la société française, les syndicats assurent beaucoup moins efficacement la défense de ses intérêts.

Une autre qualité de ce livre, à côté de la diversité des thèmes, traités avec un art de la synthèse remarquable, c'est la richesse du matériau, toujours présenté avec simplicité et une discrète ironie qui ne traduit aucun cynisme, bien au contraire. Ce livre est un modèle de plaidoyer pour un humanisme lucide. 


\section{AUTEURS}

YVES CHARBIT

POPINTER, Université Paris V 